\title{
Investigação Empírica na Ciência Jurídica. Contribuições da Sociologia Jurídica para Produção do Conhecimento não Dogmático ${ }^{1}$.
}

\author{
Miguel Ângelo Silva de Melo²; José Antônio de Albuquerque Filho ${ }^{3}$; Érika de Sá Marinho Albuquerque \\ Lielton Maia Silva ${ }^{5}$; Antoniel dos Santos Gomes Filho ${ }^{6}$
}

\begin{abstract}
Resumo: A ciência jurídica é, indubitavelmente, uma parte importante das ciências sociais, bem como está inserida no rol das ciências que estudam a humanidade a as interações sociais. Dentre os distintos métodos de investigação social, eminentemente empíricos, a observação poderá aquecer as discussões e percepções da realidade, as quais, muitas vezes, parecem ser supérfluas e distintas da tarefa da ciência jurídica. A relevância deste ensaio está na sua discussão epistemológica - revisão de literatura empírica e de investigação social - em torno do correto e possível uso de abordagens empíricas para as ciências jurídicas, as quais oferecem visíveis oportunidades para o desenvolvimento das investigações sociais no Direito. Ao longo do trabalho, concluímos que investigação empírica de natureza quantitativa e qualitativa tem uma longa tradição nas pesquisas com abordagem social, e, principalmente, nas ciências sociais aplicadas, como, por exemplo, no direito, elas ainda encontram grande dificuldade em sua adesão.
\end{abstract}

Palavras-chave: Ciência jurídica. Sociologia jurídica. Pesquisa empírica. Estudo de caso. Análise documental.

\section{Empirical Research In Legal Science. Contributions Of Legal Sociology For The Production Of Non-Dogmatic Knowledge}

\begin{abstract}
Legal science is undoubtedly an important part of the social sciences, and is embedded in the role of the sciences that study humanity and social interactions. Among the different methods of social research, eminently empirical, observation may warm up the discussions and perceptions of reality, which often appear to be superfluous and distinct from the task of legal science. The relevance of this essay lies in its epistemological discussion - review of empirical literature and social research - about the correct and possible use of empirical approaches to the legal sciences, which offer visible opportunities for the development of social investigations in law. Throughout the work, we conclude that quantitative and qualitative empirical research has a long tradition in
\end{abstract}

\footnotetext{
${ }^{1} \mathrm{O}$ estudo não teve financiamento externo, uma vez que foi todo realizado com patrocínio dos autores.

${ }^{2}$ Doutor em Sociologia pelo Programa de Pós-Graduação em Sociologia da Universidade Federal de Pernambuco. Professor do curso de Direito da Faculdade de Ciências Humanas do Sertão Central (FACHUSC). Professor do curso de Direito do Centro Universitário Dr. Leão Sampaio (UNILEÃO). Pesquisador-Líder do Laboratório Interdisciplinar em Estudos da Violência no Centro Universitário Dr. Leão Sampaio (LIEVUNILEÃO). Pesquisador-colaborador do Laboratório Interdisciplinar em Estudos Organizacionais e do Trabalho da Faculdade Vale do Salgado (LIEOT-FVS). E-mail: crioulo.miguelangelo.melo@gmail.com.

${ }^{3}$ Aluno especial do Doutorado pelo Programa de Pós-Graduação em Letras da Universidade do Estado do Rio Grande do Norte. Mestre em Direito pela Universidade Católica de Pernambuco. Professor substituto do curso de Direito da Faculdade de Ciências Humanas do Sertão Central (FACHUSC). Professor do curso de Direito da Faculdade São Francisco da Paraíba (FASP). Professor do curso de Direito da Faculdade de Filosofia, Ciências e Letras de Cajazeiras (FAFIC). Pesquisador-colaborador do Laboratório Interdisciplinar em Estudos da Violência no Centro Universitário Dr. Leão Sampaio (LIEV-UNILEÃO). E-mail: albuquerque_filho@hotmail.com.

${ }^{4}$ Aluno especial do Doutorado pelo Programa de Pós-Graduação em Letras da Universidade do Estado do Rio Grande do Norte. Mestre em Direito pela Universidade Católica de Pernambuco. Professora do curso de Direito da Faculdade São Francisco da Paraíba (FASP). Especialista em Direito Processual Civil pela Universidade Católica de Pernambuco. Docente da Faculdade São Francisco da Paraíba (FASP). E-mail. Erika-albuquerque@ hotmail.com

${ }^{5}$ Mestrando em Ciências da Saúde na Faculdade de Medicina do ABC (FMABC). Docente do curso de Psicologia da Faculdade Vale do Salgado (FVS). E-mail: lieltonmaia@fvs.edu.br;

${ }^{6}$ Mestrando em Educação Brasileira na Universidade Federal do Ceará (UFC), vinculado à Linha de História da Educação Comparada (LHEC). Discente de Licenciatura em Filosofia na Faculdade Católica de Fortaleza (FCF). Tecnólogo em Gestão Comercial pelo Centro Universitário Dr. Leão Sampaio (UNILEÃO).
}

E-mail: antoniel.historiacomparada@gmail.com.

443 Id on Line Rev. Mult. Psic. V.12, N. 40. 2018 - ISSN 1981-1179

Edição eletrônica em http://idonline.emnuvens.com.br/id 
researches with a social approach, and especially in applied social sciences, such as in law, they still find great difficulty in their adherence.

Keywords: Legal science. Legal Sociology. Empirical research. Case study. Documentary analysis.

\section{A pesquisa empírica abrindo a caixa de pandora}

A ciência jurídica é, indubitavelmente, uma parte importante das ciências sociais, bem como está inserida no rol das ciências que estudam a humanidade a as interações sociais. Muito embora se perceba que a ciência jurídica, da mesma forma que as suas irmãs sociais e humanas, é capaz de ser estudada sob o olhar especulativo, crítico, empírico, argumentativo, discursivo e lógico, sendo também possível, a partir da diversidade de métodos investigativos existentes, tecer várias considerações especulativas sobre os problemas sociais que circundam a seara jurídica e seus complexos ordenamentos jurídicos. Dentre os distintos métodos de investigação social, eminentemente empíricos, a observação poderá aquecer as discussões e percepções da realidade, as quais, muitas vezes, parecem ser supérfluas e distintas da tarefa da ciência jurídica. Fato este que fundamenta a questão sobre a importância da empiria ou do empirismo para o estudo da ciência jurídica.

Embora, na contemporaneidade, ainda seja discutível se o empirismo pode ou não pode ser completamente concebido na ciência jurídica, a pesquisa em torno de fatos sociais se torna cada vez mais precisa e necessária, principalmente no contexto de grandes transformações nas sociedades globais que se contrapõem, por um lado, discursos progressistas em defesa da diversidade em sentido de pluralismo jurídico; e por outro lado, emergem discursos conservadores e defensores de um mundo normativo. As justificações jurídicas geralmente são entendidas como sendo apenas uma função crítica. Por esta razão, segundo Raiser (2007), os métodos advindos das ciências sociais e humanas são muito mais difíceis de aplicar, tendo em vista a dificuldade normativa que está implantada e enraizada no ventre da dogmática jurídica, a qual receia que suas falhas venham a ser reconhecidas pela criticidade metodológica do positivismo empírico das ciências sociais.

Neste sentido, o sociólogo do direito aponta que os discursos argumentativos da dogmática revelam-se com "isso não pode ser o que não pode ser" (IBID, p. 11), mostrando-se, assim, um discurso frequentemente fechado pelo imperativo normativo em relação ao fato a ser 
investigado, uma vez que a percepção da realidade parece ser completamente ignorada. (BLANKENBURG, 1975). Apesar de que, desde início do século XX, proposituras neokantianas fundadas na especulação da antítese entre o Ser e do Dever Ser e no positivismo kelsiniano da lei pura do Direito, já demonstrassem que o objetivo do conhecimento enquanto reivindicação da pura doutrina jurídica caminharia, em um futuro incerto, para outros oceanos. Isto porque o defeso desta racionalidade não consegue mais encontrar em contextos globais, o sustentáculo da universalidade, que já predominou no pensamento jurídico e social de outrora na contemporaneidade. Todavia, não se é racional descontextualizarmos os efeitos que essas abordagens e escolas de pensamento deixaram em nossas sociedades, fato este, ainda hoje vem sendo claramente sentido. (GRZESZICH, 2002).

Thomas Raiser, ao sair em defesa da contribuição da sociologia jurídica, ressalta que, mesmo sendo uma ciência da lei relativamente jovem, a disciplina jurídica já demonstra positivos resultados, principalmente os que apontam achados específicos advindos da pesquisa empírica, enriquecendo, por conseguinte, as disciplinas dogmáticas que, em distintos contextos analíticos da legalidade, são tendenciosas a negarem a importância da especulação empíricolegal. Pois, mesmo diante da eminente adoção do recurso da ciência jurídica ao empirismo sociológico e suas metodologias investigativas, esse ainda é um grande empecilho de antigos e ainda dominantes pensamentos e posicionamentos da velha guarda da ciência jurídica alemã que "permanecem paralisadas em um princípio de salvaguarda da dogmática jurídica". (IBIDEM, p. 16).

A relevância deste ensaio está na sua discussão epistemológica - revisão de literatura empírica e de investigação social- em torno do correto e possível uso de abordagens empíricas para as ciências jurídicas, as quais oferecem visíveis oportunidades para o desenvolvimento das investigações sociais no Direito, a saber: a) discursivo-argumentativas (análise de discurso, análise de documental, análise histórica entre outros procedimentos); b) estudo de caso (simples, múltiplos ou únicos); ou, até mesmo, c) investigações empíricas em campo (pesquisaação, etnografia, observação participante). No entanto, devido à inexperiência da ciência jurídica em lidar com o empirismo e, respectivamente, com o uso das diversas abordagens empíricas e suas distintas propostas metodológicas de pesquisa, espera-se, neste trabalho, demonstrar como é possível que as experiência advindas das ciências sociais e humanas venham a ser aplicadas e consolidadas nas investigações jurídicas, tendo em vista que os fatos jurídicos, são, por diversas vezes, fatos ou ações sociais, provindos do conhecimento e da experiência das 
humanas, sendo que são, há muito tempo, objeto de estudo das ciências sociais, humanas e históricas, como, por exemplo, a sociologia e a antropologia ${ }^{6}$.

Finalmente, acrescenta-se que o objetivo deste ensaio é o de contribuir para a discussão cada vez mais presente no desenvolvimento das ciências jurídicas brasileiras, oportunizando, dessa maneira, os ganhos, aprendizados e riscos advindos da incorporação de metodologias investigativas que fogem ao controle da dogmática jurídica, de modo a abrir os possíveis segredos escondidos dentro da caixa de pandora a partir da investigação empírica, conforme ressaltam Glynis Breakwell, Chris Fife-Schaw, Sean Hammond e Jonathan Smith, ao justificarem as contribuições da pesquisa empírica para o desenvolvimento das ciências com foco na garantia de direitos da humanidade:

fazermos pesquisa... nós o fazemos para tentar entender o que está acontecendo... fazemos pesquisa para descobrir o que aconteceu como aconteceu e, se possível, por que aconteceu (IBID, 2010, p. 25).

Nessa perspectiva, percebe-se que uma introdução aos fundamentos da investigação social torna-se necessária para que os métodos e procedimentos de investigação social aplicados ao Direito possam ser compreendidos e replicados em investigações futuras. No final, o contributo de abordagens empíricas no campo da ciência jurídica será ilustrado por exemplos de procedimentos de investigação, tais como análise do estudo de caso e análise documental, buscando persuadir o leitor para que este se convença da necessidade e do benefício da incorporação de uma metodologia empírica e social aplicada ao Direito.

\section{A investigação social e empírica: problema, solução ou nova forma de compreensão do direito?}

A investigação empírica de natureza quantitativa e qualitativa tem uma longa tradição nas pesquisas com abordagem social - antropologia, sociologia, psicologia, pedagogia, entre outras ciências -, sendo, principalmente, nas ciências sociais aplicadas, como por exemplo, no direito, que elas ainda encontram grande dificuldade em sua adesão, em especial porque nos

\footnotetext{
${ }^{6}$ A sociologia é reconhecida como a ciência da sociedade e das sociedades humanas, isto desde o seu nascimento; já a antropologia, por sua vez, estuda a cultura produzida pelo homem nesta societas, independente do grau de desenvolvimento destas.
} 
programas de Pós-Graduação em Direito, espalhados pelo imenso país, pouca atenção é dada à pesquisa empírica no país, tendo em vista que o que se percebe é a desvalorização em relação à aplicabilidade, confiabilidade, conhecimento e descrédito dos cientistas jurídicos em relação a colaboração e aproveitamento que os distintos métodos de investigação social poderiam auxiliar e aperfeiçoar as pesquisas empíricas no Direito. (RODRIGUEZ, 2006; ADEODATO, 1999; RÜCKERT, 1995).

Marcos Nobre (2003), Alexandre Cunha e Paulo Silva (2013), Ricardo Horta, Vera Almeida, Marcelo Chilvarquer (2014) - entre outros pesquisadores nacionais - vêm debatendo bastante sobre a eminente importância em se desconstruir paradigmas, inserindo métodos e metodologias de pesquisa social para se investigar o Direito. A este respeito acentua José Rodriguez, ao proferir sua argumentação em defesa da possibilidade de se realizar pesquisa empírica em Direito, uma vez que, para o autor: “As pesquisas empíricas que tratam do Direito costumam ser classificadas como de Ciência Política, Sociologia do Direito ou Antropologia Jurídica, nunca como pesquisas em Direito". E consequentemente, o autor argumenta que é da mesma forma possível, pesquisar empiricamente no âmbito do "pensamento dogmático". (IBID., 2006, s/p). Anderson Lanzillo e Patrícia Guimarães (2014) corroboram com esta discussão ao acrescentarem que, mesmo diante de dificuldades e silêncio no meio acadêmico dos grandes e pequenos centros jurídicos do país, "a discussão acerca da realização e da qualidade da pesquisa jurídica vem tomando cada vez mais espaço” (IBID., 2014, p 18), principalmente no que diz respeito à ausência de uma formação de pesquisador no ensino e na formação do pesquisador jurídico no Brasil. Por conseguinte, surge a seguinte indagação, que é constantemente levantada em boa parte dos artigos consultados: o que deve ser uma pesquisa empírica em Direito? A resposta a esta primária indagação será dada ao longo do trabalho, quando apresentarmos duas possibilidades de pesquisa ou investigação empírica em Direito.

Paulo Eduardo Silva, ao moderar a mesa de debates durante o I Encontro de Pesquisa Empírica em Direito - a qual tinha como debatedores, os professores de distintos cursos de Direito de IES do Brasil, tais como: professor José Reinaldo de Lima Lopes (FD/USP; Direito FGV), professor Kazuo Watanabe (FD/USP), professora Maria Tereza Sadek (USP) e professor Carlos Alberto de Salles (FDRP) - acrescenta que a importância da pesquisa empírica em direito é uma realidade que cresce no Brasil desde os pioneiros estudos em finais da década de oitenta do século passado, e que o cenário político nacional, diante de incertezas e emergências, fez com que a realidade se modificasse rapidamente, dando como exemplo as invasões urbanas, 
o pluralismo jurídico, a acessibilidade à justiça, os atores do sistema de justiça, a gestão e o funcionamento de tais sistemas (morosidade, percepção da população em relação ao funcionamento do Poder Judiciário) dentre outras temáticas. Principalmente, por meio da incrementação da Constituição Federal de 1988, a qual permitiu que investigações sobre o acesso coletivo a direitos e garantias fundamentais ganhassem pauta e interesse na conjuntura jurídica, mesmo diante das dificuldades de se pesquisar empiricamente no Brasil de outrora. (SILVA, 2013).

Neste contexto de debates, a professora Maria Tereza Sadek (2013) eleva o cenário de discussões sobre as pesquisas empíricas em direito, ao se posicionar de forma crítica, principalmente, ao tratar da motivação empírica e posicionamento político-ideológico que difere desde sua origem à constituição dos cursos de direito e de ciências sociais, sua crítica destaca-se quando a professora expõe que:

\begin{abstract}
Ao contrário do que ocorreu quando da criação dos cursos de direito, a principal motivação para a constituição de cursos de ciências sociais não foi contribuir diretamente para a formação da elite dirigente. As ciências sociais foram criadas para fomentar o desenvolvimento de um espírito crítico a respeito da realidade. Não por acaso, a filosofia que orientou as primeiras escolas de ciências sociais foi uma filosofia anti-empírica. [...]. No interior dessa orientação, o direito era caracterizado como um componente da superestrutura e, portanto, era quase algo sem importância do ponto de vista daquele tipo de orientação teórica. (IBID, 2013, p. 26).
\end{abstract}

As discussões tornaram-se cada vez mais acirradas, pois, a partir da revisão da literatura, foi possível se constatar que a história do "mundo do direito" muito pouco se interseccionou com o "mundo das ciências sociais", impedindo, assim, a troca de saberes e experiências entre as duas "visões de mundo" (Weltanschaungen). Fato este que corrompeu e distanciou o desenvolvimento de pesquisas empíricas no direito. (SADEK, 2013; HERRNKIND E SCHEERER, 2003). Por outro lado, os cientistas sociais replicavam com descaso e desprezo, devido à ausência ou pouca aderência metodológica das investigações empíricas em direito, os resultados das pesquisas jurídicas, apontando nestas a ausência de confiabilidade nos resultados de trabalhos empíricos. (LAATZ, 1993). Apesar de a pesquisa empírica em direito vir ganhando, cada vez mais, espaço, prestígio e visibilidade nos Programas de Pós-Graduação em Direito na atualidade, ainda assim, percebe-se que ela é uma ameaça para a estrutura funcional que a dogmática jurídica tenta tornar imperceptível, sobretudo, porque, a partir da adoção de metodologias empíricas e investigações sociais com trabalhos de campo, torna-se possível 
perceber as falhas, os erros, e a disfuncionalidade da dogmática ou da desestruturação sistêmica do complexo sistema jurídico.

Carlos Salles (2013), corroborando com esta perspectiva, ressalta o perigo da pesquisa empírica em Direito poderá representar, tendo em vista que a sua utilização, bem como a crescente adesão, poderá "abrir a caixa de Pandora" e todos os segredos vestidos tanto pela solidão metodológica, quanto pelo isolamento da dogmática jurídica em relação à investigação empírica:

[...] a dogmática é para nós, juristas, aquele material básico de conhecimento, por meio do qual se manipula o conhecimento legal e jurídico fundamentalmente para decidir. [...]Nossa Pandora, que é a pesquisa empírica, libera a consciência de que há conceitos que não funcionam. O Judiciário, como objeto de pesquisa, desvenda-se muito distante daqueles princípios que deveria seguir. Tome-se o acesso universal à jurisdição estatal, por exemplo. A empiria desestrutura a noção de sistema que, longe dos fatos, parece funcionar. Em geral, o jurista tradicional, não gosta da pesquisa empírica, porque os dados fáticos o incomodam. (IBID, pp.30-31).

A recusa do tradicional jurista em relação à pesquisa ainda é uma realidade. Fato este que contribuiu com o objeto do presente ensaio, o qual se propõe a discutir alguns paradigmas metodológicos, os quais, conforme expostos na mesa de debate "A Pesquisa em Direito e a Pesquisa em Ciências Sociais", ainda estão presentes no imaginário investigativo de muitos cientistas tradicionalistas no Direito. Convém lembrar que, ao longo do ensaio, buscaremos apresentar uma discussão detalhada sobre o método qualitativo, em específico o estudo de caso e a análise documental, desenhando assim uma imagem holístca sobre os métodos, buscando subscrever sua eminência para o campo do Direito. A problemática em tela não visa, neste artigo, trazer à baila da discussão a necessidade de que a formação jurídica no Brasil capacite o profissional da ciência jurídica, para que este se torne um pesquisador, tampouco sai em defesa do contrário, apenas alude à possibilidade de que este, fazendo uso de metodologias distintas, oriundas das ciências sociais, possa complementar e fomentar as suas investigações sobre o sistema jurídico brasileiro, como já fazem os pesquisadores europeus ou norteamericanos. Assim, o presente ensaio visa demonstrar que é possível a realização de complexas e superficiais investigações nas distintas esferas do ordenamento jurídico brasileiro, fazendo uso de metodologias sociais, tais como as que aqui serão apresentadas, em seções próprias, a saber, dentro os inúmeros instrumentos de investigação social, destacamos o procedimento metodológico de estudo de caso e a análise documental. 


\section{Investigação empírica qualitativa no direito: breves apontamentos}

Iniciado o processo de revisão de literatura, destacamos duas formas de investigação social que poderiam solidificar distintos corpus de pesquisas empíricas com uso da abordagem qualitativa no Direito. Entre estas, evidenciaram-se a análise de documentos (processos judiciais e inquéritos policiais) e a análise do estudo de caso hábeis para se entender as subjetividades que circundam a produção do conhecimento sociológico advindo da disciplina sociológica do Direito. Todavia, destaca-se, neste cenário metodológico que alicerça a sociologia - e que pode ser muito bem usado pela sociologia jurídica - uma variedade de métodos e técnicas que podem ser usados como design da investigação e de delineamento de subjetivos em seu corpus teórico-metodológicos, tais como, por exemplo, o racismo, a intolerância e o racismo religioso, a seletividade penal, a administração judiciária, as questões de gênero e a LGBTfobia entre outros possíveis objetos e problemas de investigação empírica no Direito. Uma vez que a fenomenologia da violência está intrinsecamente ligada com a mudança social em que temas anteriormente ausentes das discussões da sociologia jurídica, adquiriram, desde as últimas duas décadas, grande destaque social, político e jurídico, aproximando, assim, as relações entre o direito e a sociedade, como bem acentua Sabadell (2005):

O sociólogo do direito só pode medir o impacto das normas jurídicas, isto é, a relevância do direito como fator de mudança social, se fizer pesquisas de opinião para saber como as pessoas se posicionam perante as leis. [...]. a intensidade da mudança depende de dois fatores gerais: da natureza do sistema jurídico que deve produzir a mudança e da situação política do momento. Quanto mais aberto, flexível e abstrato é o sistema jurídico, mais fácil será operar uma mudança social por meio de sua interpretação. (IBID., p. 101).

O Direito vem sofrendo mudanças substanciais nos diversos sistemas jurídicos, muito embora estas mudanças não estejam surtindo o mesmo efeito na sociedade (MINAYO, 2009). Da mesma forma, observamos que muitas transformações vêm sendo produzidas dentro da sociedade, todavia, estas ainda encontram grande dificuldade de serem legitimadas pelo direito, devido às estruturas normativas, os processos históricos e os juízos de valorativas que envolvem estas relações entre a Sociedade e o Direito. Assim, a partir de uma racional estrutura metodológica, é possível desenvolver diferentes investigações empíricas de cunho sociológico 
dentro do sistema jurídico, bem como sobre os efeitos, a eficácia e a adequação da sociedade às normas e, respectivamente, aos ordenamentos jurídicos específicos.

\section{Posicionamentos epistemológicos de pesquisa empírica em tensão no direito}

Entendemos ser de fundamental importância a promoção de breves considerações que poderão reforçar o entendimento do leitor sobre a decisão do pesquisador de fazer uso da metodologia qualitativa - de cunho interpretacionista -, ao invés da quantitativa de origem positivista $^{7}$. Não se pretende aqui despertar a discussão em torno da (in-) viabilidade, não cientificidade ou não operacionalidade de um método de abordagem em relação ao outro, principalmente no que se refere ao tratamento dos dados: enquanto uma metodologia nasce inspirada nas ciências da natureza, fazendo uso de premissas de que, através da observação, a operacionalização de variáveis seria possível chegar a leis universais. Estas generalizações dedutivas teriam natureza estática e que, por meio de amostragens matemáticas de natureza estatística (por exemplo, aleatórias ou representativas), seriam capazes de aproximar as relações de causa/efeito da amostra investigada; já a outra metodologia, isto é, a abordagem qualitativa, mesmo que tenha tido raízes na perspectiva positiva de conhecimento, conseguiu equilibrar a influência da abordagem quantitativa, tornando-se um método muito apropriado para avaliar problemas advindos das subjetividades humanas.

A metodologia qualitativa ganha força acadêmica, quando as investigações empíricas levaram os cientistas sociais e jurídicos a perceberem que tanto as subjetividades advindas de experiências humanas, quanto os fenômenos sociais, seriam, por si só, demasiadamente complexos e dinâmicos, para serem generalizadas por leis gerais de cunho predominantemente estatístico $^{8}$. Dentro desta perspectiva, o primeiro o posicionamento epistemológico de orientação quantitativa parte da pressuposição teórico-positiva, de que o comportamento humano seria o "resultado de forças, fatores, estruturas internas e externas que atuam sobre as pessoas, gerando determinados resultados" e que "essas forças ou fatores podem ser estudados

\footnotetext{
${ }^{7} \mathrm{O}$ positivismo do século XIX partia do princípio de que as ciências sociais deveriam buscar nos métodos objetivos, oriundos das ciências naturais, o modelo sistemático - que entendia o método (instrumento de coleta de dados) e a metodologia (potencial explicativo capaz de estudar os métodos) - a ser seguido.

${ }^{8}$ Neste sentido, Weber teve importante influencia na fundamentação da abordagem metodológica qualitativa, "ao destacar a compreensão (verstehen) como o objetivo que diferenciava a ciência social da ciência física. Segundo ele, o foco da investigação deve se centrar na compreensão dos significados atribuídos pelos sujeitos às suas ações." (André, 2005, p. 16).
} 
não somente pelo método experimental, mas também por levantamentos amostrais" (Oliveira, 2009, p. 2), oriundos das ciências naturais.

O método quantitativo se empenha em provar que os critérios da amostra e as variáveis focais - dependentes e independentes -, estabelecidas para uma determinada população, não apenas se relacionam entre si, como também são legítimas para demonstrar a representatividade da própria amostragem, operacionalizando, assim, os pressupostos de uniformidade da população pesquisada (BAUER; AARTS, 2013). Earl Babbie, ao definir o termo ciência, acrescenta que "toda ciência pretende entender o mundo ao redor. Três componentes principais constituem esta atividade: a descrição, a descoberta de regularidades e a formulação e teorias e leis" (BABBIE, 1999, p. 43). Posteriormente, o autor apresenta etapas que, em seu entendimento, permitem que o investigador conheça a verdade, ao agregar atributos caracterizadores da ciência, conseguindo, desse modo, demonstrar o porquê de a ciência social estar atrelada às mesmas regras das ciências naturais. Dentro desta linha de pensamento, entende-se que a pesquisa quantitativa é propícia para obtenção de informações, observáveis pela produção de amostras, capazes de fornecer estimativas, representativas e seguras sobre as variáveis de um todo populacional. Neste sentido, Martin Bauer e Bas Aarts elucidam que:

\begin{abstract}
A amostragem garante a eficiência na pesquisa ao fornecer uma base lógica para o estudo de apenas partes de uma população se que se percam as informações (...). A amostra representa a população como distribuição de algum critério é idêntica tanto na população como na amostra. Os parâmetros de uma população são calculados através de estimativas observadas na amostra. Quanto maior é a amostra, menor é a margem de erro destas estimativas, embora o próprio processo de amostragem possa trazer outros erros. (BAUER; AARTS, 2013, p. 41).
\end{abstract}

A partir dos entendimentos de Bauer e Aarts (2013) e Babbie (1999), é possível considerar que a representação perseguida pela pesquisa social quantitativa parte de estratégias de seleção por amostragem fundamentadas na lógica dedutiva, tal como a das ciências naturais, por buscar ser, antes de tudo, determinística, geral, parcimoniosa, específica, empiricamente verificável e intersubjetiva. (BABBIE, 1999). Já a segunda corrente de natureza interpretacionista, usualmente denominada de pesquisa qualitativa pelas ciências sociais e humanas, surge tanto no plano de debates epistemológicos, com estratégias de produção de conhecimento, como também nas discussões metodológicas, ao promover o abandono à primazia do modelo numérico e matemático no tratamento dos dados (PIRES, 2008). LionelHenri Groulx (2008) corrobora com a afirmativa de Álvaro Pires (2008), ao proferir que, na contemporaneidade, é um tanto quanto problemático a tentativa de se definir a metodologia de 
pesquisa qualitativa, preferencialmente devido ao atual estágio de desenvolvimento em que ela se encontra, onde existe vasta quantidade de métodos - semelhantes e ao mesmo tempo diferentes, ou técnicas de coleta, análise e tratamento de dados:

\begin{abstract}
A pesquisa qualitativa situa, geralmente, sua contribuição à pesquisa social, na renovação do olhar lançado sobre os problemas sociais e sobre os mecanismos profissionais e institucionais de sua gestão. (...). Ela se esforça por conferir novas funções à pesquisa social, no campo administrativo ou político, bem como produzir um novo discurso sobre o social, que esteja em consonância com a vida democrática. A contribuição da pesquisa qualitativa à pesquisa social é geralmente definida por ruptura ou por oposição à pesquisa quantitativa ou estatística. (GROULX, 2008, p. 95).
\end{abstract}

Ao perceber o homem enquanto ser ativo do processo social o qual se deseja investigar, a metodologia qualitativa consegue introduzir um novo sentido aos problemas, a partir do momento em que ela torna possível que o investigador social substitua relações de causa/efeito de uma amostra investigada (seus fatores e determinantes) pela compreensão dos significados e simbolismos da natureza em análise. Oliveira (2009) não apenas contempla o raciocínio de Groulx, como também complementa o mesmo, ao entender que foi a partir da subjetivação do homem e abandono às generalizações matemáticas, reconhecimento de peculiaridades e diferenças individuais, que os cientistas sociais foram lapidando e aprimorando, tanto a epistemologia como a metodologia de cunho qualitativo, que eclodiu no surgimento de diferentes procedimentos de investigação social, tais como: etnografia, pesquisa-ação, observação participante, entrevista do tipo qualitativo (narrativa, episódica, individual ou grupal), histórias orais de vida, grupos focais, estudo de caso e pesquisas de análise (documentos, discurso, conteúdo, análise de narrativa, análise de retórica, conversação e fala). Apesar de haver muita controvérsia entre as vantagens da abordagem quantitativa diante da qualitativa, Robert Bogdan e Sari Biklen (1994) entendem que:

\footnotetext{
Nem todos os investigadores qualitativos partilham o mesmo objetivo. (...). Ainda que existam diferenças óbvias nas diferentes abordagens à investigação qualitativa, verifica-se algum acordo entre os investigadores no tocante aos objetivos de seu trabalho. O objetivo dos investigadores qualitativos é o de melhor compreender o comportamento e experiência humanos. Tentam compreender o processo mediante o qual as pessoas constroem significados e descrever em que consistem estes mesmos significados. (IBID.,1994, p. 70).
}

Diante desta pluralidade metodológica e em busca de uma originalidade para a sua investigação empírica, percebemos, a partir da revisão bibliográfica e estudos de pesquisa 
empírica no Direito, que a grande maioria dos pesquisadores que realizaram pesquisas empíricas, decidiram-se pelo uso da pesquisa qualitativo-interpretacionista de natureza exploratória e documental, com a utilização de uma método ou fizeram opção pela triangulação de métodos, como, por exemplo, os estudos de caso (simples, único, múltiplos, entre outros), a pesquisa documental, a análise de discurso, os quais vem enriquecendo e agregando substancialmente novos valores e perspectivas para a pesquisas no Direito. (MELO, 2017).

\section{Os métodos de investigação empírica e sua interface com o direito}

\section{O procedimento de estudo de caso}

O procedimento de estudo de caso, ou case method, foi, durante algum tempo, considerado por muitos de seus críticos como um dos métodos mais pobres da grande família de investigação social de natureza qualitativa, uma vez que algumas das investigações que fizeram uso deste método não apresentavam, na propositura dos seus resultados, precisão, objetividade e rigor acadêmico capazes dar validade e confiabilidade aos resultados. Por conta disso, foram acusados como transgressores das normas e métodos típicos da epistemologia e da metodologia das ciências sociais, como expõe Robert Yin, ao considerar que este foi visto por muitos como "o irmão mais fraco dos métodos das ciências sociais". (2001, p. 10). Por conseguinte, destaca-se, a partir da revisão bibliográfica sobre as metodologias de pesquisa qualitativa que, quanto mais contemporâneos eram os artigos ou manuais de métodos e técnicas de pesquisas, menos criticado tornavam-se as referências em relação ao método de estudo de caso, principalmente por investigadores das áreas de educação, direito e administração que vêm majoritariamente defendendo e qualificando a importância e presteza do procedimento de estudo de caso. (OLIVEIRA, 2009; PIRES, 2008; BOGDAN; BIKLEN,1994).

Interessante, neste caso, é a percepção do "outro", uma vez que o estudo de caso é proposto por estes não como um método de pesquisa específica, mas como uma forma de operacionalizar informações específicas e vultosas, que podem ser facilmente negligenciadas ou modificadas perdendo, assim, a confiabilidade dos dados apresentados, como também pode realçar com fidelidade a essência do objeto em estudo: 
[...] uma unidade assume dimensões completas nas mãos do pesquisador que passa a sentir-se seguro de poder responder muito maior número de questões do que poderia fazer somente com os dados registrados. [...]. Onde o resultado, naturalmente, é uma grande tentação de extrapolar, sem garantia. (GOODE; HATT, 1969, p. 422-427).

Importante perceber que as argumentações logram em semelhanças às acusações vivenciadas pelos pesquisadores à época da expansão da abordagem qualitativa; interessante é que o case method e seus "aplicadores" foram lentamente e legitimamente ganhando espaço dentro das ciências sociais, do contrário das ciências sociais aplicadas (direito e administração), onde o método já era reconhecido há muitas décadas pelas faculdades norte-americanas que lançavam no mercado corporative lawyers "advogados de empresas", onde o discente era "tentado a pensar como advogado (to think as a lawyer). Trata-se de exercício de adestramento, reduzindo à metáfora do 'skill training"' (Bloom apud Godoy, 2004, p. 30) que preparava os melhores alunos para as melhores law firms "melhores empresas". Em adição a isto, é importante ressaltar que o case method foi criado por Christopher Columbus Langdell, em 1870, ao assumir o cargo de Decano da Harward Law School - "Escola de Direito" - pelo reitor da Harward University, senhor Charles Willian Eliot (STEVENS, 1987 Apud HORTWITZ, 1994).

Paulatinamente, segundo Silva e Benegas (2010), o case method ultrapassa as fronteiras e os liames do universo jurídico-jurisdicional e acadêmico da Harward Law School, chegando a ser incorporado pelos estudos acadêmicos na formação universitária dos grandes cursos das maiores faculdade de administração de empresas da América do Norte, a saber, pela Harward Business School, já a partir de 1910, e na Richard Ivey School of Business da University of Western Ontario, no Canadá. Corroborando com esta afirmativa Godoy acrescenta que o case method teve uma forte adesão das universidades norte-americanas, tanto em nível de formação pedagógico como metodologia de ensino, como em nível investigativo, na especialização de profissionais e capacitação para o mercado, seja ele acadêmico ou profissional:

Há cerca de cento e oitenta faculdades de direito reconhecidas pela Ordem dos Advogados dos Estudos Unidos. A maior parte delas, cerca de cem, são particulares, as demais são estaduais. A primeira delas teria surgido em 1784 quando um juiz de nome Tapping Reeve começara a lecionar em Litchfield, no estado de Connecticut. Em 1817 fundou-se em Cambridge, Massachusetts, a mais famosa de todas, Harvard, conhecida inicialmente pelo rigorismo. (...) Harvard é hoje a maior escola de direito nos Estados Unidos, contando com cerca de mil e oitocentos alunos. Yale, em New Heaven, Connecticut, é menos massificada, conta com cerca de seiscentos alunos. As outras faculdades de nome seriam Chicago, Stanford, Columbia, Michigan, Nova York, Virginia, Duke, Pensilvânia, Georgetown, Berkeley, Cornell, George 
Washington. (...) O modelo de ensino centra-se no case method. (GODOY, 2004, p. 32-33).

Silva e Benegas (IBID., 2010) elucidam que a discussão a partir da utilização do método de estudo de casos, em sala de aula ou em investigações sociais documentais não necessariamente leva a danos morais ou materiais para a(s) empresa(s) estudada(s). Uma vez que tanto professores, alunos como investigadores, não deixem de observar cuidadosamente os princípios da privacidade e da segurança de informações sobre dados numéricos, nomes, erros de estratégias comerciais. Os referidos autores consideram ainda que realizadas estas medidas de precaução protetivas nas investigações, o comprometimento da(s) empresa(s) diante do mercado competitivo não apenas seria atenuado, como também levaria a encorajar outras empresas a fazerem uso do método para a aquisição de novos mercados, visto que erros de estratégias, cometidos no passado, com uma melhoria considerável no planejamento empresarial auxiliariam o sucesso do presente e solidificaria, assim, a permanência da empresa no futuro 9 .

Desta forma, concluem ressaltando que a utilização do método de estudo de caso por empresas se presta para apontar soluções e novas possibilidades de encarar desafios, posto que estas podem ser direcionadas “(...) ao mercado, as redes de ofertas de produtos e serviços como estratégias de negociação e tomadas de decisões". (IBID., 2010, p. 17), já que, partindo de alguns pressupostos de Hammond (2001), destacam que o pesquisador, ao fazer um bom uso do método, poderá colher tanto informações quantitativas e qualitativas; além disso, terá ampla capacidade de proporcionar uma investigação social sólida e de qualidade, desde que a pesquisa esteja direcionada para um exame aprofundado do procedimento organizacional com intenção de tornar explícitas questões próprias do caso, aumentando assim, o entendimento sobre as causalidades condicionadoras do objeto de pesquisa.

Decerto que este enfoque é defendido por muitos investigadores sociais - entre eles, Grahan (2010), Jackson (2007), Godoy (2004), Horwitz (1994) e Almeida Júnior, (1947) - ao destacarem que este método ainda é, apesar de algumas críticas ${ }^{10}$, um dos mais importantes e mais promissores métodos para questões que abarquem o universo jurídico judiciário - processo

\footnotetext{
${ }^{9}$ Como estudo de caso realizado pelo professor-pesquisador Walter Kuroda sobre o "Caso Nikkey" que analisou as estratégias do Bradesco para impulsionar a adesão de clientes nipo-brasileiros que trabalhavam e residiam no Japão. (DNA CORPOTATIVO, 2004).

${ }^{10}$ Horwitz (1994, APUD GODOY, 2004) destaca que, apesar de algumas alternativas críticas que foram sendo elaboradas pelos críticos do método, principalmente nas últimas décadas da contemporaneidade, ao apontarem que o sistema de estudos de caso desencadeia um considerável aumento do nível de stress, competitividade e individualidade que leva à segregação e à humilhação de alunos que não se preparam
} adequadamente para os debates em sala de aula. 
de ensino pedagógico, processo de formação, processo de especialização profissional e processo de investigação acadêmica -, e exatamente por isso, este método se disseminou tão rapidamente nos cursos jurídicos e, posteriormente, nos cursos de gestão norte-americanos e canadianos, conforme exposto anteriormente. Assim, percebemos que inexistia um método correto, "mais ou menos útil" do que o "outro" para a construção do conhecimento; similarmente entendi que o que existia eram críticas e reservas acadêmicas de campo, fundadas, muitas vezes, na defesa de "territorialidades investigativas", a saber, "territorialidades metodológicas" no campo de investigação social, quando alguns "investigadores" tentavam impor a supremacia do seu método de conforto sobre outro.

Em Alba Zalluar (2011), vamos encontrar o seguinte esclarecimento a este respeito, quando - em seu depoimento no livro organizado por Renato Sérgio de Lima e José Luiz Ratton sobre os pioneiros nos estudos sobre crime, violência e direitos humanos no Brasil - esclarece que o "campo intelectual brasileiro" é muito complicado, sendo este um dos motivos que a fez migrar do Rio de Janeiro para Campinas, pois havia no Rio de Janeiro muitas instituições acadêmicas rivais que disputavam acirradamente o mercado investigativo e as metodologias de pesquisa dentro da própria academia:

\footnotetext{
Então achei que era um campo muito difícil e resolvi ficar estudando violência. Eu já havia me afastado da religião pelos mesmos motivos, porque era uma área muito povoada de caciques, de intelectuais muito conhecidos e hegemônicos. Aí encontrei um nicho, porque a criminalidade violenta era um campo aberto, quase que não havia ninguém escrevendo, especialmente naquilo que eu fazia. (IBID., 2011, p. 60).
}

Como caracteriza, na mesma obra, Sérgio Adorno, ao atestar a existência da disputa ou da reserva de mercado investigativo no Brasil dentro da própria academia. Principalmente em relação à questão da "territorização" entre profissionais das ciências sociais e do direito, quando se propõem a estudar a 'justiça, violência e crime'. Somado a isso, vale mencionar que o pesquisador é enfático ao ressaltar que, no tempo hodierno e globalizado, não se tem como fugir as evidências de 'olhares' transversais e interdisciplinares em torno de vários temas, sendo que seria utópico tentar aceitar a existência de um objeto exclusivo por uma determina disciplina (IBID., 2011). Trabalhar com o método do estudo de caso propriamente dito, conforme orienta Merriam (1988), é estar ciente de que esta forma de investigação qualitativa, apesar de se prestar a direcionar um determinado objeto por instrumentos que permitem uma "observação detalhada de um contexto, ou indivíduo, de uma única fonte de documentos ou acontecimento 
específico" exige certo conhecimento sobre o objeto, mecanismos e estruturas provedoras e peculiares ao próprio objeto. (APUD BOGDAN; BIKLEN, 1994).

Corroborando com esta visão, Martins (2008) recomenda que a simples confrontação de dados ou de informações não é suficiente, sendo, pois, necessário ir mais além, saber observar, observar captando nuances imperceptíveis. Levando o pesquisador a ter certeza de estar adotando um olhar minimamente imparcial. Lembrando que, para isso, é consideravelmente necessário ter paciência, principalmente quando se pretende, com exatidão, analisar documentos com o uso do método de estudo de caso:

\section{O observador deve ter competência para observar e obter dados e informações com imparcialidade, sem contaminá-los com suas próprias opiniões e interpretações. Paciência, imparcialidade e ética são atributos necessários ao pesquisador. (MARTINS, 2008, p. 24).}

Oliveira (2009) sugestiona, dentro desta perspectiva, acerca da existência de alguns problemas metódicos que podem afetar o desenvolvimento da investigação - com uso do método de estudo de caso -, caso o pesquisador inexperiente não esteja completamente atento aos instrumentos válidos, necessários e convincentes para agregar valores de confiabilidade à pesquisa, além de satisfação das exigências normativas de cunho ético, fundamentais para o estudo envolvendo indivíduos, unidades de análise e dados pesquisados. Diferentemente do que ocorre com a utilização do método de estudo de caso em caráter pedagógico (ensino/ aprendizagem) na universidade, SHAPIRO (1988, p. 01) acrescenta que quatro etapas sequenciam a obrigatoriedade para o êxito do case method em sala de aula, que se iniciaria com a) Fase inicial de preparação para análise; b) Fase pré-postulatória (discussão com pequenos grupos); c) Fase Postulatória (discussão com a sala toda) e d) conclusões generalizadas que seriam extraídas do aprendizado.

Já Oliveira (2009) Martins (2008), André (2005) determinam que, além do “protocolo de campo", que tem a funcionalidade de ser o mecanismo orientador e regulador das fases processuais que alicerçam a própria investigação, existiram, pelo menos, três fases extremamente necessárias para a aplicabilidade do método de estudo de caso que, uma vez seguidos, auxiliaria no amadurecimento, na expansão dos sentidos e na contribuição do relatório da própria pesquisa para posteriores estudos, a saber: a) Fase inicial (fase exploratória); b) Fase deliminatória (coleta de dados) e, finalmente, a c) Fase de análise dos dados (sistematização dos dados). Partindo das concepções acima expostas e tomando os devidos cuidados em se 
atentar para as fases enunciadas como necessárias, constatou-se que é possível fazer uso deste procedimento quando se tem como objetivo a promoção de uma investigação que envolva interpretações sobre "a palavra escrita a fim de discorrer sobre a construção do discurso empreendido por determinados grupos sociais (...)", somando-se a estes, a "utilização de processos judiciais a partir da experiência (...).” (OLIVEIRA; SILVA, 2005, p. 244).

\section{O procedimento de análise documental}

De todo modo, salienta-se que a utilização do método de análise documental torna possível que o pesquisador do Direito venha a fornecer outro olhar sociológico a sua investigação, principalmente no que diz respeito ao tratamento de dados (informações, signos, simbologias e significados), os quais, muitas vezes, se perdem em virtude de diferentes contextos ou conjunturas sociopolítico e jurídicas. Sobretudo em casos de crimes, tais como, por exemplo, crimes motivados pelo ódio motivados pelo racismo, intolerância religiosa, orientação sexual e/ou identidade sexual das vítimas. Diante desses fatores de relevância social, observa-se a necessidade de se analisar os documentos, uma vez que as narrativas, os discursos argumentativos, os dialogismos presentes em documentos podem ressignificar a investigação empírica a ser realizada.

Entretanto, mesmo entendendo que a memória e lembranças estariam presentes em narrativas e falas de vários atores sociais, exempli gratia como familiares, companheiros, amigos, militantes do movimento social e/ou técnicos judiciários (peritos, delegados, advogados, defensores, promotores e juízes) envolvidos nestes crimes. Acredita-se ser prudente e gratificante, a recuperação das falas e dos significados existentes nas falas presentes nos documentos (tais como, ações de preconceito, de hostilidades e de discriminação) e, respectivamente, possível de ser detectado a partir das análises de narrativa, retórica e conteúdo. Partindo de semelhante percepção Cellard (2008) ressalta que

\footnotetext{
As capacidades da memória são limitadas e ninguém conseguiria pretender memorizar tudo. A memória pode também alterar lembranças, esquecer fatos importantes, ou deformar acontecimentos. Por possibilitar realizar alguns tipos de reconstrução, o documento escrito constitui, portanto, uma fonte extremamente preciosa para todo pesquisador das ciências sociais. (IBID, p. 295).
}

A partir de estudos, tais como as contribuições de investigações qualitativas documentais nacionais e internacionais nas ciências jurídicas, humanas e sociais, percebem-se 
o crescente número e contribuições que, cada vez mais, empenham-se em demonstrar a utilidade deste método na produção de investigações empíricas. Neste sentido, compreende-se que os estudos documentais, além de se prestarem para organização e interpretação do material em vista do objetivo que se deseja encontrar, consegue também fornecer informações e significados que passariam despercebidos, impossíveis e/ou inteligíveis pela narrativa advinda do recurso da memória. Complementando este raciocínio, demarcando fronteiras e apresentando suas vantagens, Kelly desenvolve pressuposições no ensaio epistemológico organizado por Gauthier (1984 APUD CELLARD, 2008) a respeito da análise documental, ao referendar que este recurso qualitativo traz consigo várias atribuições:

Trata-se de um método de coleta de dados que elimina, ao menos em parte, a eventualidade de qualquer influência - a ser exercida pela presença ou intervenção do pesquisador - do conjunto das interações, acontecimentos ou comportamentos pesquisados, anulando a possibilidade de reação do sujeito à operação de medida. (KELLY APUD GAUTHIER, 1984, p. 296-297).

Em consonância com esta perspectiva, objetiva-se aqui promover uma aproximação à realidade fática a partir da perspectiva da sociologia jurídica, sobre contemporâneas transformações que marcam tanto o direito, como a própria sociedade, bem como as dinâmicas e as reformas em torno das concepções sociais e jurídicas, verbi gratia, do crime, da criminalidade, do criminoso, do controle social e da vítima. Neste sentido, Ramón Soriano (1997) apresenta o seguinte esquema sobre as variáveis persentes em suas investigações sociológicas sobre as relações entre o as transformações sociais que ele presenciou no Direito:

[...] a) O direito é uma variável dependente, ou seja, um fenômeno social que muda constantemente em função de outros fenômenos. A relação entre os grupos e as classes sociais, definidas principalmente pelo fator econômico, determina as estruturas jurídicas. $\mathrm{O}$ direito pode ser então considerado como um produto de interesses sociais, que dependem das relações de dominação em cada sociedade. [...]; b) apesar de ser uma variável dependente da estrutura social-cultural, o direito possui uma autonomia relativa e, por consequência, pode induzir a mudanças sociais. [...]. As teorias que mais insistiram na visão do direito como produto socialmente determinado, são justamente aquelas que, quando tentaram aplicar as suas ideias na prática política, utilizaram o direito como meio para produzir fortes mudanças sociais. (IBID., p. 311 APUD SABADELL, 2005, p. 98).

Pesquisadores das ciências sociais que trabalham com a perspectiva sociológica do Direito, ressaltam que a influência do Direito nos processos sociais, podem culminar com a legitimação de normas de vanguardas, como também de normas conservadoras, onde outros mecanismos sociais podem equilibrar ou desequilibrar a legitimidade e eficácia destas normas 
jurídicas. (Melo, 2017). Assim, percebe-se que as metodologias qualitativas se prestam, mesmo ainda tendo um caráter marginal em relação a outros métodos, para a avaliação destas transformações sociais, seja de avanço, seja de retrocesso legal. (LÜDKE; ANDRÉ, 1986). Mas afinal, o que é e como a análise de documento poderá ser empreendida em uma investigação social qualitativa de natureza jurídico-normativa, tendo como objeto crimes de investigação, os sistemas jurídicos (penal, civil, administrativo, previdenciário, constitucional, empresarial) entre outros problemas encontrados no Direito?

Uwe Flick (2009) responderia que sim a esta indagação, a partir do momento em que entende que, ao longo de nossas vidas em sociedade, produzidos uma série de documentos, desde o nosso nascimento até o nosso óbito, passamos por diferentes fases com diversos momentos de sociabilidade, nos quais documentos são produzidos, tais como documentos pessoais, diários de fotografias, cartões e correspondências comemorativas, que podem ser analisados tanto de forma quantitativa como de forma qualitativa na investigação social. Por seu caráter multiuso e por trazer consigo direta ou indiretamente outros métodos e técnicas de análise (tais como: narrativa, retórica e discurso), que podem ser ou não utilizados pelo investigador social, sem perder necessariamente o sentido de sua natureza metodológica no tratamento e na produção dados, será dado ênfase apenas à análise de conteúdo dos documentos em estudo. (MELO; ALMEIDA; SILVA; TEIXEIRA, 2017).

De modo que se debita assim, a análise documental o caráter de método autônomo, por navegar brilhantemente entre a indução quantitativa e a dedução qualitativa.

\footnotetext{
Se tivermos que arcar com a natureza dos documentos, então precisaremos afastarnos de um conceito que os considere como artefatos estáveis e pré-definidos. Em vez disso, devemos considerá-los e termos de campos, de estruturas e de redes de ação. De fato, o status das coisas enquanto "documentos" dependem precisamente das formas como esses objetos estão integrados nos campos de ação, e os documentos só podem ser definidos em relação a esses campos (PRIOR, 2003, APUD FLICK, 2009, p. 231).
}

Sá-Silva, Almeida e Guindani (2009) alegam que o uso da pesquisa documental, mesmo que ainda pouco valorizado e apreciado no âmbito das ciências sociais, é capaz de resgatar informações passíveis de serem interpretadas, favorecendo e ampliando o entendimento sobre objetos cujo tratamento de dados poderá enriquecer os contextos históricos, culturais e sociais, apesar de reconhecer dificuldades acadêmicas em lidar com documentos. (MELO; GOMES FILHO; LÔBO, 2016). Para explicar com claridade o posicionamento, os autores recorrem a 
May (2004, p. 206), visto que este reconhece a dificuldade, por parte de alguns pesquisadores sociais, em lidarem com este procedimento, a saber:

Não é uma categoria distinta e bem reconhecida, como a pesquisa survey e a observação participante. Dificilmente pode ser considerada como constituindo um método, uma vez que dizer se utilizará documentos e não dizer nada como eles serão utilizados. (MAY, 2004, APUD SÁ-SILVA; ALMEIDA; GUINDANI, 2009, p. 3).

Verificamos que existem discordâncias entre pesquisadores sobre o melhor tratamento a ser dado à análise documental, pois, conforme já enunciado anteriormente, não será feito um aprofundamento na discussão, muito menos a mesma será transformada em questão problema que mereça ser debatida, uma vez que este não é o objetivo do presente capítulo desta tese, todavia creu-se ser prudente apresentar estas diferentes perspectivas. (MELO, 2017). Para fundamentar esta indagação metodológica, os autores, acima citados, ratificam que sobre a "análise qualitativa de documentos", as referências bibliográficas sobre metodologia da investigação social, demonstram que inexiste uma homogeneidade por parte dos especialistas da área em suas categorizações relacionadas ao uso de documentos, onde os termos se revezam entre pesquisa documental, método documental, técnica documental e análise documental (IBID., 2009, p. 3).

Cellard (2008) se antecipa à Flick (2009), ao evidenciar que a análise documental em investigação qualitativa, além de conseguir facilitar a interpretação do social vivenciado pelo homem em estudo, seja como sujeito ou como objeto, permite que seja realizada uma interpretação de toda a conjuntura envolvida e enriquecendo um determinado processo.

O documento escrito constitui uma fonte extremamente preciosa para todo pesquisador nas ciências sociais. Ele é, evidentemente, insubstituível em qualquer reconstrução referente a um passado relativamente distante. Pois, não é raro que ele represente a quase totalidade dos vestígios da atividade humana em determinadas épocas. Além disso, muito frequentemente, ele permanece como o único testemunho de atividades particulares ocorridas num passado recente. (CELLARD, 2008, p. 295)

Ainda no que tange ao debate anteriormente exposto, e por acreditar que uma boa investigação social deve, pelo menos, tentar interligar os objetivos e hipóteses de sua investigação tanto com o referencial teórico, como a metodologia utilizada, acredita-se que o pesquisador poderá conseguir uma aproximação a esse postulado científico. Seguindo este raciocínio, Appolinário (2009) acrescenta que: 
As pesquisas possuem duas categorias de estratégias de coleta de dados: a primeira refere-se ao local onde os dados são coletados e, neste item, há duas possibilidades: campo ou laboratório. (...). A segunda refere-se à fonte dos dados: documental ou campo. Sempre que uma pesquisa se utiliza apenas de fontes documentais (livros, revistas, documentos legais, arquivos em mídia eletrônica). (...). Quando a pesquisa não se restringe à utilização de documentos, mas também se utiliza de sujeitos (humanos ou não) diz-se que a pesquisa possui estratégia de campo. (APPOLINÁRIO, 2009, p. 85).

Por exemplo, presenciamos cada vez mais frequentemente investigações no Direito, sendo realizadas por pesquisadores que fazem uso de procedimentos metodológicos da investigação social, os quais vêm contribuindo e muito com a ciência jurídica, principalmente, quando estas conseguem apontar as complexidades e as variabilidades sociais presentes nos diversos e complexos sistemas do ordenamento jurídico. De tal modo que estas investigações vêm elevando com uma inquestionável riqueza dos dados em seus resultados e achados a ciência jurídica.

De fato, compreendemos que a Sociologia do Direito e no Direito pode trazer reais, racionais e fundamentais contribuições, uma vez que ela está recheada de mecanismos ferramentas e subsídios - capazes não apenas de auxiliar na propositura de novas descobertas, como também em fomentar a formulação de novos horizontes e novos problemas jurídicos. Certamente, a adoção da interdisciplinaridade metodológica na pesquisa empírica é um ganho para a ciência jurídica e para a sociedade, principalmente, quando esta ação é capaz de promover a abertura da "caixa de pandora da dogmática jurídica" e de auxiliar na instrumentalização de novas propostas para a transformação ou solidificação do Direito, como apregoa Bárbara Baptista (2010):

\begin{abstract}
A tradição do ensino jurídico, dogmático, fecha as perspectivas do conhecimento. O Direito é por demais hermético, daí a dificuldade de reconhecer e legitimar outros campos do conhecimento, mesmo sendo cediço o fato de se tratar, o Direito, de uma disciplina que não pode se compreender a partir de sua própria estrutura, lógica e sistemática interna. O Direito é um campo, de certo modo, indisponível. Pesquisar no Direito implica desvendar mecanismos que o sistema não quer que sejam desvendados. Dessa forma, realizar pesquisa empírica no Direito, além de incomum, é desafiante e, a meu ver, é o caminho possível, melhor dizendo, é o que permitirá tornar um pouco mais disponível um campo ainda muito distante da sociedade ao qual se aplica. (IBID., p. 131).
\end{abstract}

Maskaro (2007) corrobora com esta perspectiva, pelo fato de que é necessário observar que as "Weltanchaungen" (visões do mundo) dentro da ciência jurídica podem - pela adoção da 
pesquisa empírica - ser ampliadas, permitindo, dessa maneira, que o jurista consiga refletir sobre outras formas de sociabilizar a compreensão das normativas jurídicas e seus efeitos de eficácia, eficiência e aceitabilidade em sociedade. Pois, se observamos o velho brocardo romano "onde há sociedade, há direito", ressaltaremos que a compreensão do Direito é uma tarefa que não se restringe apenas a sua normatização, mas também, a sua "empirização" e a sua relação tanto com a sociedade, quanto com o meio ambiente que o insere na sociedade a partir das realidades que o cercam, que o alimentam e que o sistematizam, em um constante processo de (re)construção e evolução. Isto porque a sociologia do direito consegue fazer com que o Direito dialogue com outras questões ou problemas técnicos, que a fixação na dogmática do "mero direito positivo" o impede de fazer, uma vez que a investigação empírica "não é um pensamento qualquer de juristas sobre a sociedade", mas sim, "deveria ser um pensamento dos juristas e sociólogos" sobre alguns ou algum "fenômeno jurídico na sociedade" (MASKARO, 2007, p. 22).

\section{Conclusão}

As considerações finais a que chegamos, ao término deste ensaio, representam, em maior ou em menor significância, os argumentos discursivos utilizados como meta nas investigações empíricas sociais e jurídicas que estamos realizando nos últimos cinco anos junto ao Laboratório Interdisciplinar de Estudos da Violência (Liev/ Unileão). Isto de tal forma que, ao longo deste período, publicamos cinco livros e muitos artigos, os quais trazem sempre à rubrica e possibilidade de se inserir novas epistemologias no Direito, entre estas, fizemos uso e demos destaque à diversidade metodológica que propiciaram e alimentaram o nosso desejo em realizar investigação empírica, com abordagens qualitativa e quantitativa no Direito.

Primeiramente, constatamos a importância que a investigação empírica deve ter na ciência jurídica, mesmo diante dos riscos e desafios, a empiria pode trazer grandes contribuições para a produção do conhecimento jurídico, mais humano e menos preso ao positivo das leis, se levarmos em consideração o desenvolvimento histórico da ciência jurídica a nível internacional nas últimas décadas, observarmos que ela está inserida no campo de tensão entre concepções e correntes teóricas conservadoras e liberais, que finda por dificultar o próprio desenvolvimento da ciência. 
Por conseguinte, buscamos apresentar, neste ensaio, a contribuição cientifica de que é possível experimentar dentro da complexidade e contingência normativa do sistema jurídico, novos mecanismos e trajetórias metodológicas que podem auxiliar o Direito a ressignificar a sua composição em relação a outros olhares sobre o Direito.

Assim, em terceiro lugar, ressaltamos que a empiria na ciência jurídica - seja pelo método da observação, seja pelo procedimento da descrição (documental, discursiva, experimental) ou pela pesquisa in loco em um campo específico (etnográfica) entre outras formas - pode aproximar a realidade do cientista do Direito, uma vez que a empiria é uma realidade cientifica que, há muito tempo, encontrou guarida nas ciências humanas e sociais, e que ainda luta, de modo generalizante, por um reconhecimento na ciências jurídica.

Quarto, corroboramos da premissa de que a empiria evidencia a compreensão de muitos processos sociais, os quais infelizmente não são absorvidos, tampouco encontram representação da realidade nas posturas teóricas e nas práticas de muitos profissionais do mundo jurídico, com exceção dos que trabalham com foco na antropologia jurídica e na sociologia do Direito.

Em quinto lugar, constamos que se abordagens empíricas não estão atingindo os seus objetivos, tampouco, apresentado resultados satisfatórios, dentro da complexa e vasta seara da ciência jurídica, estas podem, sem sombra de dúvidas, estar sendo mal aplicadas e, talvez, devido à inexperiência do (da) pesquisador(a), por isso, devem ser evitadas.

Finalmente, chegamos à conclusão final de que independentemente do que foi exposto e defendido durante este artigo, este não se propõe a negar, muito menos a condenar a utilização de outros métodos de investigação no Direito, que não se fundamente na empiria; pelo contrário, evidenciamos que é de um substancial aumento de investigações empíricas na ciência jurídica, esta metodologia permanece com pouca aderência nos diversos campos da carreira jurídica.

\section{Referências}

ADEODATO, J. M. L. Bases para uma metodologia da pesquisa em direito. Revista CEJ, V. 3 n. 7 jan./abr. 1999.

ADORNO, S. Trajetória intelectual e representações no Campo da Segurança Pública, p. 7697. In R. S. d. Lima; J. L. Ratton, J. L. (Org.). As ciências sociais e os pioneiros nos estudos sobre crime, violência e direitos humanos no Brasil. São Paulo: ANPOCS, 2011. 
ALMEIDA JÚNIOR, A. A propósito do ensino de direito nos Estados Unidos. In Revista da Faculdade de Direito da Universidade de São Paulo, ano 1947, v. 42, p. 125 - 159, 1997.

ANDRÉ, M. E. D. Estudo de Caso em Pesquisa e avaliação educacional. Brasília: Livraria Editora 2005.

APPOLINÁRIO, F. Dicionário de metodologia científica: um guia para a produção do conhecimento científico. São Paulo: Atlas, 2009.

BABBIE, E. Métodos de pesquisas de survey. Tradução de Guilherme Cezarino. Belo Horizonte: Ed. UFMG, 1999.

BAPTISTA, B. G. L. A pesquisa empírica no Direito: obstáculos e contribuições. In: R. Kant de Lima, L. Eilbaum, L. Pires. (Org.). Conflitos, Direitos e Moralidades em Perspectiva Comparada (p. 127-152, v. II). 1 Ed. Rio de Janeiro: Garamond Universitária, 2010.

BAUER, M. W.; Aarts, B. A construção do corpus: Um princípio para a coleta de dados qualitativos. In: M. W. Bauer; G. Gaskell (Org.). Pesquisa qualitativa com texto: imagem e som: um manual prático. Tradução de Pedrinho A. Guareshi. 11. Ed. Petrópolis, RJ: Vozes, 2013.

BLANKENBURG, E. Die Aktenanalyse. In: E. Blankenburg (Hg.). Empirische Rechssoziologie. München: Die öffentliche Verwaltung, 1975.

BLOOM, A. The closing of the american mind. New York. Touchstone Book, 1987. APUD. A. S. d. M. Godoy. Direito e educação jurídica nos Estados Unidos. In Revista Sequencia n. 48, p. 2940, 2004.

BOGDAN, R. C; BIKLEN, S. K. Investigação Qualitativa em Educação. Tradutores Maria João Alvarez, Sara Bahia dos Santos e Telmo Mourinho Baptista. Porto-Portugal: Editora Porto, 1994.

BREAKWELL, G., FIFE-SCHAW, C., HAMMOND, S., Smith, J. (Orgs.). Métodos de Pesquisa em Psicologia. Trad. Felipe Rangel Elizalde. Consultoria, supervisão e revisão técnica: Vitor Geraldi Hasse. 3 Ed. Porto Alegre: Artmed Bookman, 2010.

CELLARD, A. A análise documental. In: J. Poupart et. al. (Org.). A pesquisa qualitativa: Enfoques epistemológicos e metodológicos. Tradução Ana Cristina Nasser. Petrópolis-RJ: Editora Vozes, 2008.

CHIZZOTI, A. Pesquisa qualitativa em ciências humanas e sociais. Petrópolis: Vozes, 2006. DNA Corporativo HSM Management. São Paulo, n. 47, p. 19-28, 2004. Disponível em: http://www.hsmmanagement.com.br.

FLICK, U. Uma introdução à pesquisa qualitativa. Porto Alegre, Artmed, 2009.

GAUTHIER, B. Recherche sociale - De la problématique à la collecte des donnés. Québec: Presses de l’Universitpe du Québec, 2008. In: A. Cellard A análise documental. In: J. Poupart et. al. (Org.). A pesquisa qualitativa: Enfoques epistemológicos e metodológicos. Tradução Ana Cristina Nasser. Petrópolis-RJ: Editora Vozes, 2008. 
GODOY, A. S. d. M. Direito e educação jurídica nos Estados Unidos. In: Revista Sequencia n. 48, p. 29-40, 2004.

GOODE, W. J.; HATT, P. K. Métodos em Pesquisa Social. Fortaleza: Editora Biblioteca Universitária, 1969.

GRAHAM, A. Como escrever e usar estudos de caso para ensino e aprendizagem no setor público. Brasília: ENAP, 2010.

GROULX, L.-H. Contribuição da pesquisa qualitativa à pesquisa social. In J. Poupart et. al. (Org.). A pesquisa qualitativa: Enfoques epistemológicos e metodológicos. Tradução Ana Cristina Nasser. Petrópolis-RJ: Editora Vozes, 2008.

GRZESZICH, B. Rechte und Ansprüche. Eine Rekonstruktion des Staatshaftungsrechts aus den subjektiven öffentlichen Rechten. Beiträge zum Öffentlichen Recht. Tübingen: Mohr Siebeck, 2002.

HAMMOND, J. S. Lerning by the Case Method. Harvard Business School, n 9-376-241, rev April 16, 2002.

HELDER, R. R. Como fazer análise documental. Porto: Universidade de Algarve, 2006.

HORTA, R. d. L. e; Almeida, V. R. d. \& Chivarquer, M. Avaliando o desenvolvimento da pesquisa empírica em direito no Brasil: o caso do Projeto Pensando o Direito. Revista de Estudos Empíricos em Direito, p.162-183. Brazilian Journal of Empirical Legal Studies vol. 1, n. 2, jul, 2014.

HORWITZ, M. The transformation of american law - 1780 - 1860. New York: Okford University Press, 2. Vols, 1984.

JACKSON, J. D. Socrates and Langdell ilegal writing: is the socratic method a proper tool for legal writing courses? In California Western Law Review. V. 43, n. 2. pp. 267-308, 2007.

LAATZ, W. Empirische Methoden: ein Lehrbuch für Sozialwissenschaftler. Frankfurt am Main: Thun Deutsch, 1993.

LIMA, R. S. D. L.; Ratton, J. L. As Ciências Sociais e os pioneiros nos estudos sobre crime, violência e direitos humanos no Brasil. São Paulo: ANPOCS, 2011.

LÜDKE, M/ André, M.E.D. A. Pesquisa em Educação: abordagens qualitativas. São Paulo: EPU, 1986.

MARTINS, G. A. Estudo de caso: uma estratégia de pesquisa. 2. Ed. São Paulo: Atlas, 2008.

MASKARO, A. L. Lições de Sociologia do Direito. São Paulo: Quartier Lantin, 2007.

MELO, M. A. S.; ALMEIDA, A. J. R. d.; SILVA, C. R. d.; TEIXEIRA, E. G. F. d. A. Hate Crimes, uma ressiginficação ou nova representação da Criminologia e do Direito Penal Internacional no contidiano Brasileiro?, p. 141-162. In: M. A. S. d. Melo; A. S. Gomes Filho; Z. F. QUEIROZ, Z. F. (Orgs.). Epistemologias em confronto no direito: reinvenções, ressiginificações e representações a partir da interdisciplinaridade. Curitiba: CRV, 2017. 
MELO, M. A. S. Representações sociais da violência contra homossexuais no Judiciário: um estudo de caso de crime de ódio homofóbico no Estado do Ceará. Tese (Doutorado). Universidade Federal de Pernambuco. Programa de Pós-Graduação em Sociologia (PPGS/ UFPE. Centro de Filosofia e Ciências Humanas. Orientador: Prof. Dr. Gustavo Gomes da Costa Santos. Recife, 2017.

MELO, M. A. S.; COSTA, J. R. F.; DIAS, K. M. SILVA, I. O. M. Bullying escolar sob o enfoque da sociologia da violência: um estudo no Programa ProJovem na cidade de Juazeiro do Norte/CE (p. 245-276). In M. A. S. d. Melo; A. S. Gomes Filho; C. É. A. Lobo, Cecília Érika D’Almeida. (Orgs.). Saberes e Dizeres no Cariri Cearense: Gênero, Religiosidades, Africanidades e Segurança Pública. Curitiba: CRV, 2016.

MERRIAM, S. Case study research in Education: A qualitative approach. San Francisco, CA: Jossey Bass, 1988.

MINAYO, M.C. S (Org.). Pesquisa social: métodos e técnicas. 3. Ed. São Paulo: Atlas, 2009.

NOBRE, M. et al. O que pesquisa em direito? São Paulo: Quartier Latin, 2005.

OLIVEIRA, C. L. d. Um apanhado teórico-conceitual sobre a pesquisa qualitativa: Tipos, Técnicas e Características. In Travessias. UNIOESTE. Online, 2000.

OLIVEIRA, C. L. d. Um apanhado teórico-conceitual sobre a pesquisa qualitativa: Tipos, técnicas e características. In Revista Travessias. UNIOESTE. Educação, cultura, linguagem e arte, ed. 04, online, 2009.

OLIVEIRA, F. L. d.; Silva, V. F. Processos Judiciais como fonte de dados: poder e interpretação. In: Sociologia, Porto Alegre, ano 7, nº. 13, jan/jun 2005, p. 244-159.

PIMENTEL, A. O método de análise documental: seu uso numa perspectiva histórica. Cadernos de Pesquisa, n. 114, p. 179 - 195, nov. 2001.

PIRES, Á. P. Sobre algumas questões epistemológicas de uma metodologia geral para as ciências sociais. In: J. Poupart et. al. (Org.). A pesquisa qualitativa: Enfoques epistemológicos e metodológicos. Tradução Ana Cristina Nasser. Petrópolis-RJ: Editora Vozes, 2008.

PRIOR, I. Using Documents in Social Research. London, 2003.

RAISER, T. Grundlagen der Rechtssoziologie, 4. Aufl. Tübingen: Mohr Siebeck, 2007

RODRIGUEZ, J. R. Pesquisa empírica e estado de direito: A dogmática jurídica como controle do poder soberano. In CONPEDI - Congresso Nacional de Pós-Graduação em Direito, Amazonas, 2006.

RÜCKERT, J. Abbau und Aufbau der Rechtswissenschaften nach 1945, p. 1251-1259. In: Neue Juristische Wochenschrift, München: Verlag C. H. Beck, 1995.

SÁ-SILVA, J. R.; ALMEIDA, C. D. D.; GUINDANI, J. F. Pesquisa Documental: Pistas teóricas e metodológicas. In: Revista Brasileira de História \& Ciências Sociais. Ano I, Número I, Julho, 2009. 
SCHEERER, S.; HERRNKIND, M. Mehr Sicherheit vor Polizeigewalt: das Grundproblem, konkrete Diagnosn und praktische Reformvorschläge. Eine Eileitung, p. 5-21. In: M. Herrnkind, S. Scheerer (Hg.), Die Polizei als Organisation mit Gewaltlizenz. Möglichkeiten und Grenzen der Kontrolle. Hamburger Stiftung zur Förderung von Wissenschaft und Kultur. Münster, Hamburg und London: LIT Verlag, 2003.

SHAPIRO, B. P. An Introduction to Cases. Harvard Business Scholl, n. 9-399-077, November 5, 1998.

SILVA, P. E. I Encontro de Pesquisa Empírica em Direito, p. 78-98. In: A. d. S. Cunha, A. d. S.; P. E. (Coord. e Org.). Pesquisa Empírica em Direito. Rio de Janeiro: Ipea, 2013.

SILVA, R. R. d.; BENEGAS, A. A. O uso do estudo de caso como método de ensino na graduação. In: Economia \& Pesquisa, v. 12, n. 12, p. 9-31, novembro, 2010.

SILVERMAN, D. Interpretação de dados qualitativos: métodos para análise de entrevistas, textos e interações. Tradução Magda França Lopes. Porto Alegre: Artmed, 2009.

SORIANO, R. Sociología del Derecho. Barcelona: Ariel, 1997.

STEVENS, R. B. Law school: Legal education in America from 1850s to 1980. Chapel Hill: The University of North Carolina Press, 1987.

YIN, R. K. Estudo de caso - planejamento e métodos. 2. ed. Porto Alegre: Bookman, 2001.

ZALLUAR, A. Trajetória intelectual e representações no Campo da Segurança Pública, p. 58-75. In R. S. d. Lima; J. L. Ratton, J. L. (Org.). As ciências sociais e os pioneiros nos estudos sobre crime, violência e direitos humanos no Brasil. São Paulo: ANPOCS, 2011.

\section{Como citar este artigo (Formato ABNT):}

MELO, Miguel Ângelo S. de; ALBUQUERQUE FILHO, José Antônio de; ALBUQUERQUE, Érika de Sá M.; SILVA, Lielton Maia; GOMES FILHO, Antoniel dos Santos. Investigação Empírica na Ciência Jurídica. Contribuições da Sociologia Jurídica para Produção do Conhecimento não Dogmático.. Id on Line Rev.Mult. Psic., 2018, vol.12, n.40, p.443-469. ISSN: 1981-1179.

Recebido: 10/04/2018

Aceito 17/04/2018 